\title{
Mechanical Integrity of Thermal Barrier Coatings: Coating Development and Micromechanics
}

\author{
Torben Fiedler, Joachim Rösler, Martin Bäker, Felix Hötte, \\ Christoph von Sethe, Dennis Daub, Matthias Haupt, Oskar J. Haidn, \\ Burkard Esser, and Ali Gülhan
}

\begin{abstract}
To protect the copper liners of liquid-fuel rocket combustion chambers, a thermal barrier coating can be applied. Previously, a new metallic coating system was developed, consisting of a NiCuCrAl bond-coat and a Rene 80 top-coat, applied with high velocity oxyfuel spray (HVOF). The coatings are tested in laser cycling experiments to develop a detailed failure model, and critical loads for coating failure were defined. In this work, a coating system is designed for a generic engine to demonstrate the benefits of TBCs in rocket engines, and the mechanical loads and possible coating failure are analysed. Finally, the coatings are tested in a hypersonic wind tunnel with surface temperatures of $1350 \mathrm{~K}$ and above, where no coating failure was observed. Furthermore, cyclic experiments with a subscale combustion chamber were carried out. With a diffusion heat treatment, no large-scale coating delamination was observed, but the coating cracked vertically due to large cooling-induced stresses. These cracks are inevitable in rocket engines due to the very large thermal-strain differences between hot coating and cooled substrate. It is supposed that the cracks can be tolerated in rocket-engine application.
\end{abstract}

T. Fiedler (凶) · J. Rösler · M. Bäker

Technische Universität Braunschweig, Institute of Materials, Braunschweig, Germany e-mail: t.fiedler@tu-braunschweig.de

F. Hötte · M. Haupt

Technische Universität Braunschweig, Institute for Aircraft Design and

Lightweight Structures, Braunschweig, Germany

C. von Sethe · O. J. Haidn

Technical University of Munich, Chair of Space Propulsion, Munich, Germany

D. Daub · B. Esser · A. Gülhan

Supersonic and Hypersonic Technology Department, German Aerospace Center (DLR), Institute of Aerodynamics and Flow Technology, Köln, Germany

(C) The Author(s) 2021

N. A. Adams et al. (eds.), Future Space-Transport-System Components

under High Thermal and Mechanical Loads, Notes on Numerical Fluid Mechanics

and Multidisciplinary Design 146, https://doi.org/10.1007/978-3-030-53847-7_19 


\section{Introduction}

Copper liners of liquid fuel rocket engines are subjected to high thermomechanical loads which can lead to damage by blanching [1-3] or the so-called doghouse effect [4-9]. To avoid failure, a thermal barrier coating (TBC) may be applied on the inner surface of the combustion chamber. This coating reduces the maximum temperature of the copper liner and protects the surface against oxidation and erosion.

In the past, several different TBC systems for rocket engine application were developed and tested (for a detailed review, see [10, 11]). These studies show that extreme test conditions are necessary to investigate realistic coating failure. However, in most cases, a detailed elucidation of the observed coating damage is missing.

The main goal of the present research project was to develop an improved coating system based on the findings from the literature and gain a deep understanding of coating failure mechanisms for future coating design. This was done in three steps:

In a first step, state of the art thermal barrier coatings, consisting of a NiCrAlY bond-coat and a zirconia top-coat, were tested to gain a better understanding of the coating failure mechanisms [12-14]. A laser test bed has been set up to test the coatings with a thermal gradient [13], and a micro model was developed to investigate interface stresses between substrate and coating which led to delaminations during the laser tests [12].

In a second step, an improved thermal-barrier coating system was developed, consisting of a NiCuCrAl bond-coat and a Ni-based superalloy top-coat $[11,12,15$, 16].

In a third step, a detailed study of the possible failure mechanisms of the new coating system was performed, and a failure model for coating design and lifetime analysis was set up [10]. For this purpose, the laser test bed was modified to increase the heat flux density (up to $30 \mathrm{MW} / \mathrm{m}^{2}$ ) and the thermomechanical loads in the coatings $[11,17]$. Although the very high heat fluxes in rocket combustion chambers (up to $150 \mathrm{MW} / \mathrm{m}^{2}$ ) could not be reproduced, the laser experiment goes beyond many other laboratory-scale experiments.

To investigate the coating damage in the laser cycling experiments in more detail, finite element simulations were carried out $[11,17]$. For these simulations, material parameters for the coating system were determined. For this purpose, aluminium substrates were coated and removed in dilute $\mathrm{NaOH}$ solution to get free standing coatings [18]. These free standing coatings were investigated e.g. in tensile and compression tests, vibrating-reed experiments, dilatometric and laser-flash measurements at different temperatures to obtain an extensive set of material parameters [11, 17, 19].

In the laser cycling experiments, four different damage mechanisms were observed $[10,11,20]$ : Delamination cracks along the substrate/coating interface, diffusion caused interface porosity, large scale buckling, and vertical cracks in the coatings.

Delamination cracks grow due to the different coefficients of thermal expansion of substrate and coating in the roughness profile of the interface [10]. These cracks were observed after thermal cycling at interface temperatures of $700{ }^{\circ} \mathrm{C}$ and above 
$[10,11]$. The growth of delamination cracks can be hindered by a diffusion layer between coating and substrate [11]. A heat treatment of $6 \mathrm{~h}$ at $700{ }^{\circ} \mathrm{C}$ is sufficient to avoid delamination in the laser tests even at interface temperatures of $800^{\circ} \mathrm{C}$ [10].

Interface porosity becomes relevant after long heat exposure: due to the Kirkendall effect [21-24], pores can form on a large area at the substrate/coating interface, reducing the layer adhesion. In addition, the heat conductivity through the interface is reduced by the pores, resulting in overheating of the overlying layer. The formation of pores can be avoided (assuming maximum accumulated hot-gas times of $<6 \mathrm{~h}$ ) if the interface temperatures are kept below $750^{\circ} \mathrm{C}$ [11]. The bond coat/top coat interface is also susceptible to pore formation, but only at temperatures above $1000^{\circ} \mathrm{C}$.

Buckling of the coatings is caused by the high temperature difference between the hot coating and the cold substrate and thus large thermal compressive strains. If these strains exceed a critical value, the layer bends and buckles. The critical compressive strain or the critical elastically stored energy is massively reduced by small imperfections at the substrate/layer interface. For a detailed discussion see e.g. [10]. According to the current state of research, it is assumed that the coating system considered here requires massive interface damage to buckle in the laser experiments [10]. Consequently, to prevent buckling, it is sufficient to prevent damage to the interface (buckling and interface porosity, see above).

Vertical cracks are a result of large cooling stresses near the coating surface. During the heating phase, the high compressive strains in the hot coating can exceed the yield strength. The resulting plastic deformation leads to the formation of tensile strains in the coating during subsequent cooling, which can cause vertical cracks [10]. At room temperature, the critical elastic strain at which vertical cracks occur is about $0.55 \%$ [10]. At higher temperatures, higher critical strains can be expected as the coatings become increasingly ductile with increasing temperature [18].

In this article, exemplarily, a coating system was designed for a $1000 \mathrm{kN}$ full scale liquid fuel combustion chamber to demonstrate the benefits of a thermal barrier coating. The mechanical loads in the coatings are quantified by finite element simulations, and possible coating failure is estimated. Furthermore, the coatings were tested in two validation experiments with a hot-gas flow: an arc heated supersonic wind tunnel and a subscale combustion chamber.

\section{Methods}

\subsection{Coating Process}

The coatings were applied with high velocity oxyfuel spray (HVOF). HVOF produces relatively dense coatings (porosity $<1 \%$ ) with a good adhesion and an oxide content $<1 \%[16,25,26]$.

The materials for the HVOF process were fed in powder form. The bond coat material is a newly developed $\mathrm{NiCuCrAl}$ alloy [15], the top-coat material is a $\mathrm{Ni}$ - 
Table 1 Coating materials

\begin{tabular}{l|l|l|l}
\hline Material & Composition $($ wt.- $\%)$ & Particle size $(\mu \mathrm{m})$ & Manufacturer \\
\hline NiCuCrAl & Ni-30\%Cu-6\%Al-5\%Cr & $+20 /-50$ & Nanoval (custom powder) \\
\hline Rene80 & Ni-14\%Cr-9.5\%Co-5\% $\mathrm{Ti}$ & $+11 /-45$ & $\begin{array}{l}\text { Oerlikon Metco } \\
\text { (Diamalloy 4004 NS) }\end{array}$ \\
& $4 \%$ Mo-4\%W-3\%Al & & \\
\hline
\end{tabular}

Table 2 Coating parameters

\begin{tabular}{l|l|l|l|l}
\hline Material & Fuel $(\mathrm{l} / \mathrm{h})$ & Oxygen $(\mathrm{slpm})$ & $\begin{array}{l}\text { Comb. chamber } \\
\text { pressure }(\mathrm{MPa})\end{array}$ & $\begin{array}{l}\text { Spray distance } \\
(\mathrm{mm})\end{array}$ \\
\hline $\mathrm{NiCuCrAl}$ & 16.2 & 650 & 0.50 & 400 \\
\hline Rene80 & 18.0 & 680 & 0.55 & 300 \\
\hline
\end{tabular}

based superalloy Rene80 [27]. The compositions and the sizes of the powder are shown in Table 1. A WokaStar 610 gun from Sulzer Metco (now known as Oerlikon Metco) was used for coating application. The coating parameters were established in preliminary studies (see e.g. [28]) and are shown in Table 2.

\subsection{Arc Heated Hypersonic Wind Tunnel}

For the wind tunnel tests, $200 \mathrm{~mm} \times 200 \mathrm{~mm} \times 1 \mathrm{~mm}$ Incoloy $800 \mathrm{H}$ plates were coated on one side. To increase the coating adhesion and avoid the growth of delamination cracks, the samples were diffusion heat treated for $0.5 \mathrm{~h}$ at $800^{\circ} \mathrm{C}$.

The arc-heated wind tunnel L3K at DLR, Cologne [29], was used to obtain the required aerothermal loads. The experiments were conducted at Mach 7.7, a free stream temperature of $477 \mathrm{~K}$, a pressure of $50.3 \mathrm{~Pa}$, and a flow velocity of $3756 \mathrm{~m} / \mathrm{s}$. The model was subjected to the flow for $120 \mathrm{~s}$ at an angle of attack of $20^{\circ}$. The panel surface temperature was measured using an infrared camera. For details on the sample geometry and the experiments see $[30,31]$.

\subsection{Subscale Combustion Chamber}

The coatings were tested on a realistic cooling channel geometry in a hot-gas flow in a subscale combustion chamber. The rectangular combustion chamber is designed to disassemble and exchange a test segment as part of the chamber wall. This test segment is made of the copper alloy $\mathrm{CuCr} 1 \mathrm{Zr}$ and has a realistic cooling channel geometry for nitrogen as coolant. For details on the test bench and the experimental conditions, see [3]. 
The coating was applied on the hot-gas side of the test segment. Prior to coating application, the surface of this segment was ground with P800, rinsed in acetone, and grit blasted to remove thick oxide layers and impurifications. The front edge oriented towards the hot-gas flow was rounded $(0.5 \mathrm{~mm}$ radius $)$ to enhance the coating adhesion on this critical edge. The sample was masked using metal sheets and adhesive tape (aluminium tape for grit blasting, fibre-reinforced high-temperature tape during coating application). The sample was cooled with pressurized air in the internal cooling channels during coating process. Tests with prototypes showed that this cooling is sufficient to keep the temperature in the copper substrate below $200^{\circ} \mathrm{C}$ during the coating process.

After the spray process, the coating surface was ground and polished to achieve a roughness of $R a 0.5 \mu \mathrm{m}$. Afterwards, the sample was diffusion heat treated for $6 \mathrm{~h}$ at $700^{\circ} \mathrm{C}$ in an $\operatorname{argon}(\mathrm{Ar} 4.8)$ atmosphere to enhance the coating adhesion.

The coated test panel was tested in the combustion chamber for 36 cycles. One cycle consists of pre cooling, $27.5 \mathrm{~s}$ hot-gas phase, and post cooling.

\section{Coating Design for a Large Scale Combustion Chamber}

To demonstrate the benefits of thermal barrier coatings (TBC) in rocket combustion chambers, a coating system was designed for a virtual $1000 \mathrm{kN}$ oxygen/hydrogen combustion chamber with a maximum wall heat-flux density of $92 \mathrm{MW} / \mathrm{m}^{2}$. This combustion chamber was designed to demonstrate different cooling concepts and thermal barrier coatings. Thus, without a TBC, the temperature of the copper liner would exceed the maximum service temperature of $800 \mathrm{~K}$ [32].

The coating design was carried out for the throat region, where the maximum temperatures and heat fluxes could be expected. Finite element simulations were performed on an FE model of a rocket combustion chamber segment according to Ref. [11, 17]. Geometry data and boundary conditions like heat transfer coefficients, fluid temperatures and pressures were provided by project K4 [33].

Assisted by the finite element simulations, a coating system with an overall thickness (bond-coat and top-coat) of $150 \mu \mathrm{m}$ was found to be optimal for this application. Here, the coating reaches a maximum surface temperature of $1353 \mathrm{~K}$. A higher coating thickness would lead to an overheating of the coating near the hot-gas surface. The bond-coat was $45 \mu \mathrm{m}$ thick, according to previous work. A higher bond-coat thickness would increase the maximum temperature of the bond-coat material and has no benefit for the coating behaviour.

According to the FEM simulations, the $150 \mu \mathrm{m}$ thick TBC reduces the maximum temperature of the copper liner by approximately $200 \mathrm{~K}$, from 962 to $760 \mathrm{~K}$. The maximum wall heat-flux density is reduced from 92 to $70 \mathrm{MW} / \mathrm{m}^{2}$. 


\subsection{Mechanical Loads}

Figure 1 shows the in-plane elastic strain and the temperature in a $150 \mu \mathrm{m}$ thick coating during one simulated combustion cycle of the $1000 \mathrm{kN}$ chamber. The elastic strain is plotted for a point near the hot-gas surface since the maximum loads were observed here.

The cycle starts at room temperature and $\varepsilon_{e l .11}=0$ (Point (A) in Fig. 1). Due to the pre cooling prior to ignition, small tensile strains are induced in the coating, caused by the different coefficient of thermal expansion (CTE) of coating and substrate. The transient maximum of these stresses is caused by the fact that the thin combustion chamber wall cools down faster than the surrounding nickel jacket. After ignition, the coating's temperature increases rapidly whereas the copper liner is still cooled, so that large compressive strains are induced in the coating (B). At (C), the yield strength of the coating is exceeded. With further heating, the temperature dependent yield strength decreases, and plastic deformation reduces the elastic strain although the overall mechanical strain is still increasing. At maximum temperature (D), the elastic strain is $\varepsilon_{e l .11}<0.1 \%$, whereas the plastic strain is $\varepsilon_{p l .11} \approx 2 \%$. After the end of the hot-gas phase, the coating cools down and thermal contraction leads to large elastic tensile strains. At point (E), the yield strength is exceeded and plastic deformation is calculated in the FEM simulations. In reality, it can be expected that the coatings crack instead of plastic deformation, but this could not be considered in the FEM simulations due to the lack of reliable crack-related material parameters. The critical elastic strain for vertical cracks in the coatings is approximately $0.55 \%$ (see

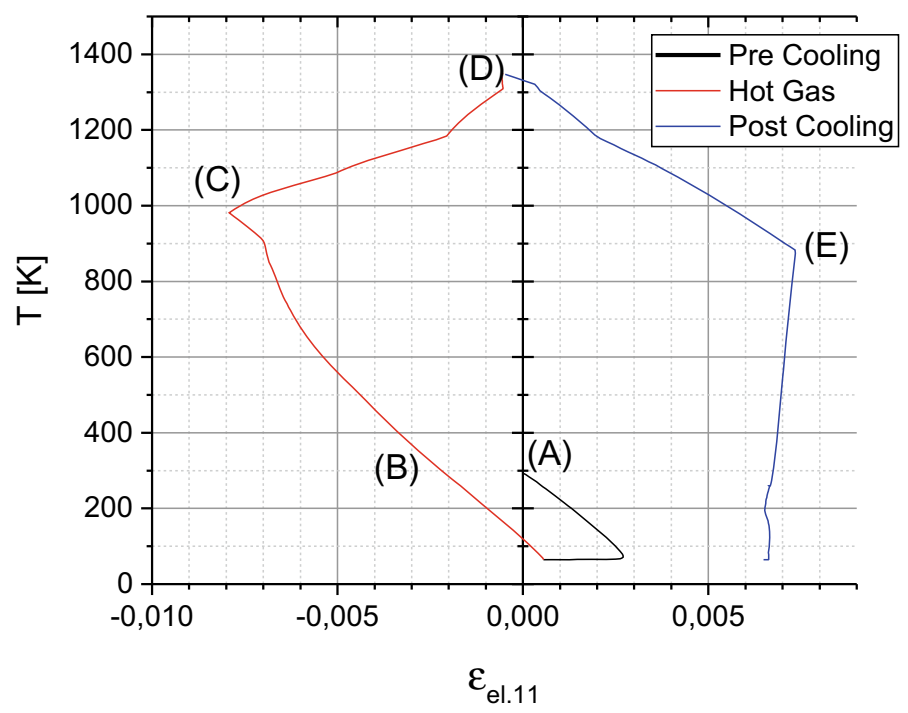

Fig. 1 Elastic strain parallel to the coating surface and temperature for a point near the coating surface during one combustion cycle, including pre cooling, hot-gas phase and post cooling 
introduction), which is exceeded here. Consequently, vertical cracks are inevitable. Even thinner coatings showed tensile strains larger than the critical value for crack growth.

\subsection{Crack Propagation}

The discussion above showed that it is inevitable that coatings crack vertically near the hot-gas surface. Due to the lack of reliable material data for crack propagation in the coatings, it was not possible to model crack growth in the FEM simulations. Instead, the stress gradient through the coating after cooling down was investigated, see Fig. 2: The stress is maximal near the coating surface where the highest temperature and thus the largest plastic deformation occurs during the hot-gas phase. With increasing distance from the surface, the stresses decrease. With higher coating thickness, the stress near the substrate/coating interface becomes less, caused by the lower temperature during the hot-gas phase due to the larger thermal insulation.

It can be estimated with the stress intensity factor whether the cracks will stop near the substrate interface. For plasma sprayed metallic coatings, the critical stress intensity factor for crack propagation is $K_{I c}=1$ to $10 \mathrm{MPa} \sqrt{\mathrm{m}}$ [34]. Although data for HVOF-sprayed coatings were not available, it can be assumed that $K_{I c}$ is even larger due to the lamellar microstructure. For $K_{I c}=10 \mathrm{MPa} \sqrt{\mathrm{m}}$, the critical stress for crack propagation is for all crack lengths $>10 \mu \mathrm{m}$ below the stress in Fig. 2, so that the cracks would propagate towards the substrate with the assumed $K_{I c}=$ $10 \mathrm{MPa} \sqrt{\mathrm{m}}$. A value of $K_{I c}>17 \mathrm{MPa} \sqrt{\mathrm{m}}$ would be sufficient to stop the cracks in the bond coat for $150 \mu \mathrm{m}$ thick coatings. This shows that future work has to focus on the one hand on the measurements of $K_{I c}$, and on the other hand, the bond-coat should be modified to achieve a $K_{I c}$ as high as possible.

\subsubsection{Influence of Vertical Cracks on the Combustion-Chamber Life Time}

It was supposed previously [10] that vertical cracks in the coating can be tolerated as long as they do not proceed into the substrate. These vertical cracks are also observed in "classical" TBC applications for example on turbine blades (segmentation cracks) [34] where they are tolerated, because they increase the strain tolerance of the TBC and thus the coating lifetime.

In rocket combustion chambers, these cracks can also be tolerated as long as the copper substrate is not damaged by crack propagation or oxidation, and as long as the coating adhesion is not worsened by crack kinking.

Due to the high ductility of the copper substrate, a crack propagation is not likely. With $K_{I c}=145 \mathrm{MPa} \sqrt{\mathrm{m}}$ [35], the stresses in the copper substrate have to exceed $5 \mathrm{GPa}$ for crack propagation under static loading, far beyond the actual calculated stresses (see Fig. 2). This was confirmed in tensile tests on coated $\mathrm{CuCr} 1 \mathrm{Zr}$ sheets 


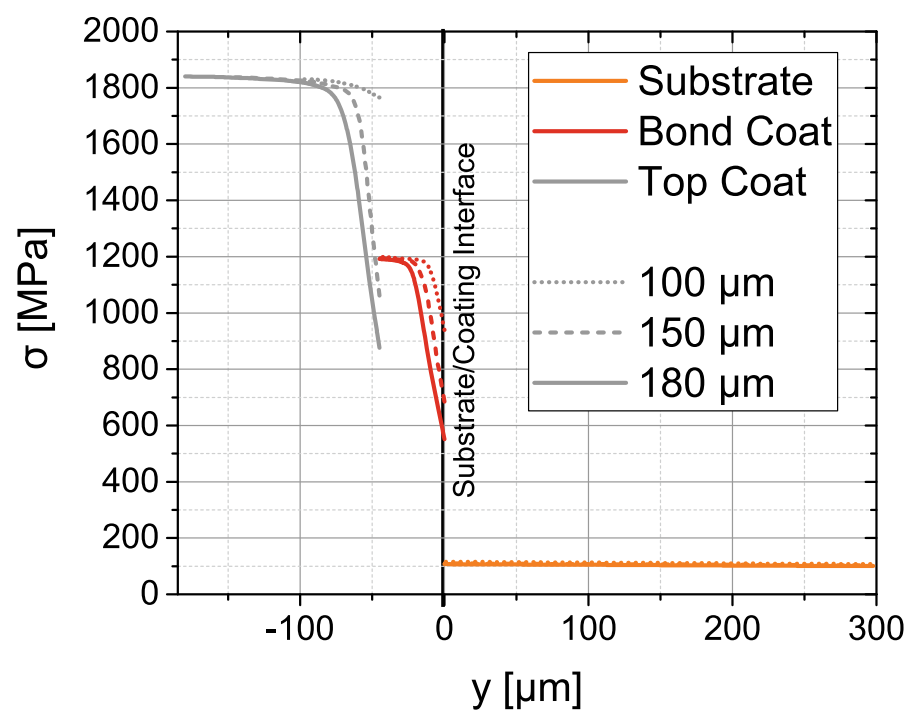

Fig. 2 Stress parallel to the coating surface along the cross section through the combustion chamber wall for different coating thicknesses after cooling down. Taken from the FEM simulations without crack modelling

(see ref. [10] for a description of the experiments), where stresses up to 460 MPa led to vertical cracks in the coating, but no crack propagation into the substrate. However, the effect of cyclic loading needs further clarification.

In "classical" TBC-applications in gas turbines, a hot-gas intake into the cracks is relevant, since the cracks open during the hot-gas phase [36]. Due to the larger temperature gradient in rocket combustion chamber walls, the coatings are under large compressive loads during the hot-gas phase so that the cracks are closed again, and the danger of hot-gas intake is reduced.

\section{Validation Tests}

To investigate the coating behaviour in real hot-gas flow conditions, and to validate the conclusions from the coating failure model, two validation tests were carried out: In an arc heated hypersonic wind tunnel, coated panels were heated by the hot-gas flow to investigate the durability of the coatings in hypersonic flow conditions at surface temperatures above $1300 \mathrm{~K}$. In a subscale combustion chamber, the coatings were tested on test panels with a realistic cooling-channel geometry to investigate their behaviour in combustion chambers with a near steady-state wall heat-flux. 


\subsection{Arc Heated Hypersonic Wind Tunnel}

The coatings designed in Sect. 3 reach surface temperatures of up to $1350 \mathrm{~K}$. It had previously been assumed [37] that the maximum tolerable temperature of the top-coat surface is $1423 \mathrm{~K}$, but experimental evidence was still missing.

The arc heated hypersonic wind tunnel experiment was used to expose the coatings to a supersonic gas-flow and to large surface temperatures to investigate the behaviour of the coatings under these harsh conditions. Figure 3 shows the surface temperature on the coating during the experiments. The hypersonic flow heats the panel to above $1350 \mathrm{~K}$. The local temperature maximum/distribution results from the interaction of surface deformation and flow field [31]. Due to thermal expansion, the coated plate buckled with an amplitude $>10 \mathrm{~mm}$ causing additional loads on the coatings.

A microscopical inspection of the coating surface after the wind tunnel experiment showed no erosion or coating damage. Figure 4 shows a cut through the coating at $x=40 \mathrm{~mm}$ and $y=0$ (according to Fig. 3 ). The coating morphology did not change, and no degradation by erosion could be observed.

The experiments show that the coatings can withstand surface temperatures of $1350 \mathrm{~K}$ under supersonic flow conditions.

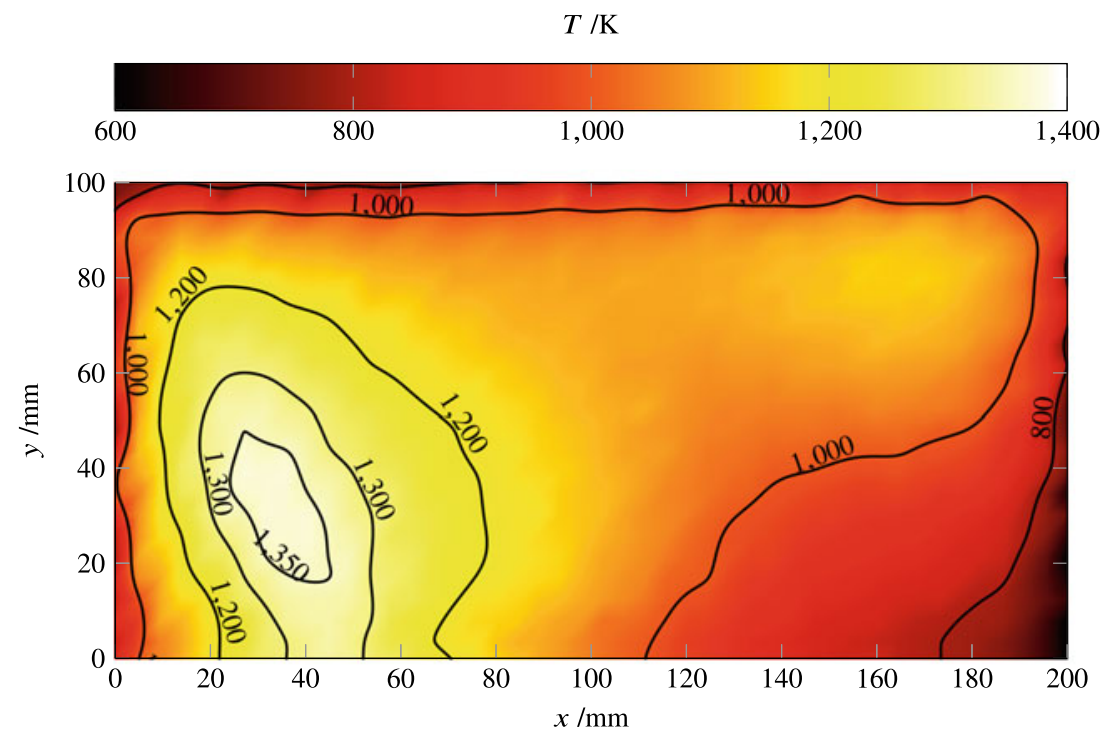

Fig. 3 Maximum surface temperature of half a test plate during the wind tunnel tests. The temperature dependent emissivity of the coating material was measured near the maximum temperature. Measurements at lower temperatures are less accurate (more details in [30]) 


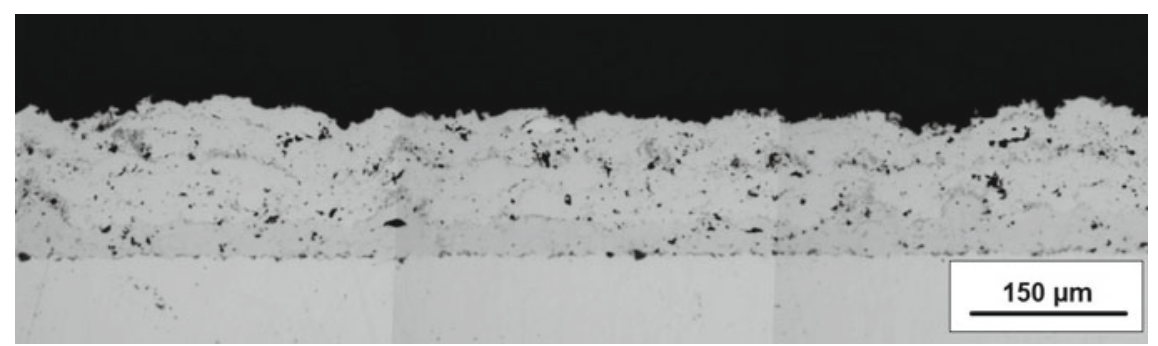

Fig. 4 Cross section of the coating after one cycle in the wind-tunnel experiment at surface temperatures of $1300-1350 \mathrm{~K}$

\subsection{Subscale Combustion Chamber}

As discussed in Sect.3, vertical cracks are inevitable in combustion chambers due to the large plastic strains at high temperature. It was assumed that these cracks can be tolerated in rocket engines as long as they do not lead to a substrate damage or coating delamination.

To validate these assumptions, the coating system was tested in a subscale combustion chamber. The results from the whole test campaign including also many tests with uncoated test panels are also to be published in [9]; in the following, the coated specimen is investigated in more detail.

Since a coating in an as-sprayed condition showed poor adhesion in preliminary tests and delaminated within one cycle [9], the experiments were carried out on a

Fig. 5 Coating surface after 36 cycles in the subscale combustion chamber: Vertical cracks, no coating loss, copper deposits at the front edge

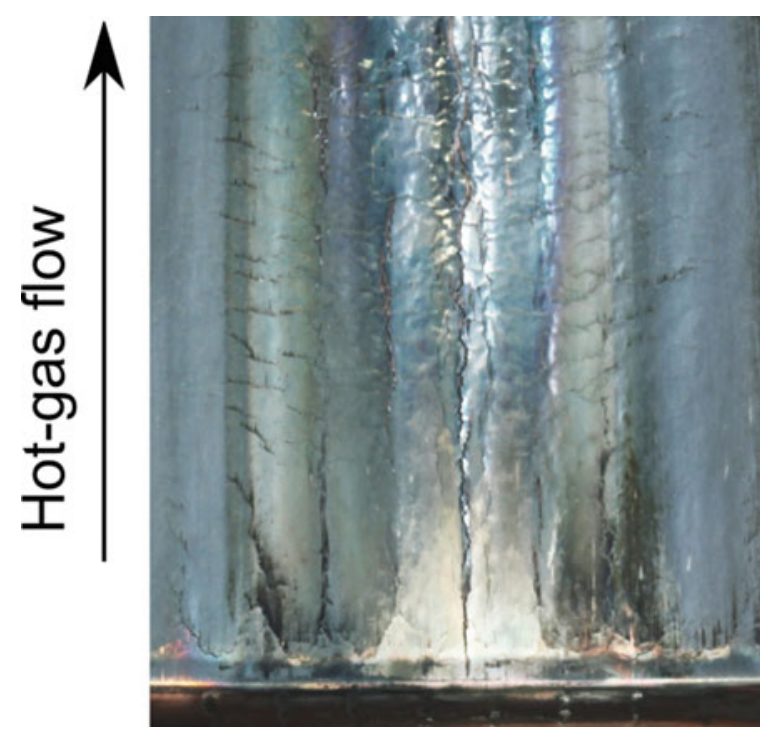


diffusion heat treated coating. As expected, vertical cracks could be observed in the coating after the first cycle. With additional cycles, more cracks became visible, but the coating was still adhering to the copper substrate even after 36 cycles (Fig. 5). Although a dense crack network formed in the coating, no oxidation or degradation of the copper substrate could be observed. Copper-coloured spots at the front edge (Fig. 5 bottom) are deposits from the upstream part of the combustion chamber.

Since the subscale test chamber was originally designed to provoke a damage of the cooling channel [3], the thin combustion chamber wall buckled in some areas. This caused a partial delamination of the coatings, see Fig. 6.

The heat flux and thus the temperature gradient was small compared to large scale combustion chambers. Consequently, also the stress gradient in the coating was small and the crack propagation cannot be compared to large scale engines as in Sect. 3. However, some of the cracks stopped before reaching the copper substrate, but mostly, the cracks propagated to the substrate interface (Fig. 7 top).

In some cases, the cracks kinked and propagated along the interface, or propagated into the substrate (Fig. 7 bottom). It is expected that this effect is driven by thermomechanical fatigue during the 36 test cycles. Furthermore, the temperature in the copper wall was $975 \mathrm{~K}$ [9], far above the maximum service temperature of

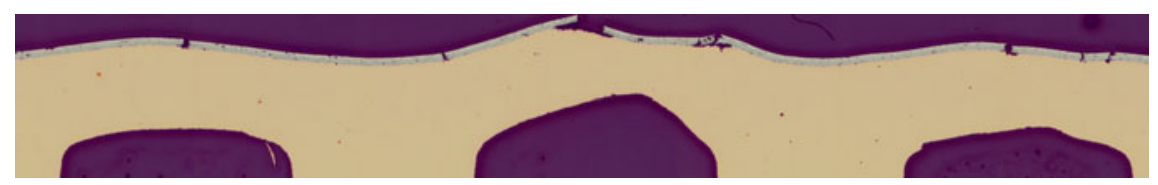

Fig. 6 Cross section through the central cooling channels: Large deformation of the thin copper wall caused partial coating delamination

Fig. 7 Vertical cracks in the coating after the thrust-chamber tests. Top: the crack reaches the substrate. Bottom: the crack kinks and propagates along the interface, and a crack grows into the substrate

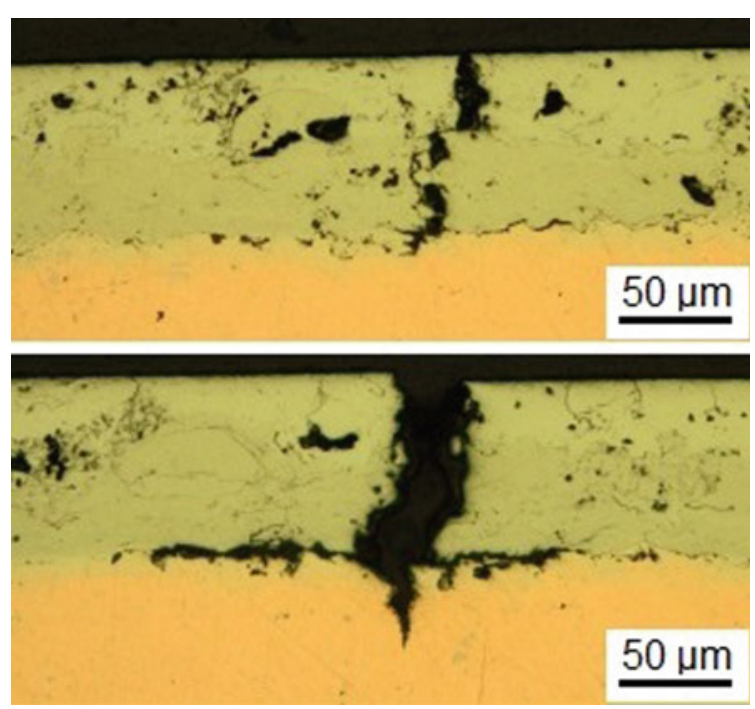


the copper liner in large scale rocket engines ( $800 \mathrm{~K}$, see Sect. 3). Thus, thermomechanical fatigue plays a major role in the subscale experiments due to these harsh conditions.

\section{Conclusions}

A thermal barrier coating (TBC) for rocket combustion chambers was designed and possible coating failure modes were discussed. In validation experiments with an arc heated supersonic wind tunnel and a subscale combustion chamber, the coatings were tested under more realistic conditions compared to preliminary tests in a laser test bed. It was shown in simulations that a $\mathrm{TBC}$ can reduce the maximum surface temperature of copper liners by up to $200 \mathrm{~K}$. Vertical cracks in the coatings are inevitable, but can be tolerated. A delamination of the coating was avoided by a diffusion heat treatment. Furthermore, it was shown that the TBC withstands supersonic flows even at surface temperatures of $1350 \mathrm{~K}$.

\section{References}

1. Ogbuji, L.: Oxidation of Metals 63(5-6), 383 (2005)

2. Duval, H.: Investigation on blanching on cryogenic engines combustion chamber inner liner. Dissertation Ecole Centrale Paris (2014)

3. Hötte, F., Fiedler, T., Haupt, M.C., Lungu, P., Sethe, C.V., Haidn, O.J.: J. Propul. Power 35(5), 906 (2019)

4. Schulz, U., Fritscher, K., Peters, M., Greuel, D., Haidn, O.: Sci. Technol. Adv. Mater. 6(2), 103 (2005)

5. Fassin, M., Kowollik, D., Wulfinghoff, S., Reese, S., Haupt, M.: Arch. Appl. Mech. 86, 2063 (2016)

6. Kuhl, D., Riccius, J., Haidn, O.J.: J. Propul. Power 18, 835 (2002)

7. Quentmeyer, R.J.: NASA Report Technical Memorandum. NASA TM-100933 (1988)

8. Jain, P., Raj, S.V., Hemker, K.J.: Acta Materialia 55, 5103 (2007)

9. Hötte, F., Sethe, C.V., Fiedler, T., Haupt, M.C., Haidn, O.J., Rohdenburg, M.: Int. J. Fatigue (submitted 2020)

10. Fiedler, T., Rösler, J., Bäker, M.: J. Therm. Spray Technol. 28(7), 1402 (2019). https://doi.org/ 10.1007/s11666-019-00900-1

11. Fiedler, T.: Wämedämmschichten für Raketentriebwerke. Niedersächsisches Forschungszentrum für Luftfahrt (2018)

12. Schloesser, J.: Mechanische Integrität von Wärmedämmschichten für den Einsatz in Raketenbrennkammern. Der Andere Verlag (2014)

13. Schloesser, J., Bäker, M., Rösler, J.: Surf. Coat. Technol. 206, 1605 (2011)

14. Schloesser, J., Fedorova, T., Bäker, M., Rösler, J.: J. Solid Mech. Mater. Eng. 4(2), 189 (2010)

15. Fiedler, T., Fedorova, T., Rösler, J., Bäker, M.: Metals 4, 503 (2014)

16. Fiedler, T., Bäker, M., Rösler, J.: In: SIMULIA Community Conference (2015)

17. Fiedler, T., Bäker, M., Rösler, J.: Surf. Coat. Technol. 332, 30 (2017)

18. Fiedler, T., Sinning, H.R., Rösler, J., Bäker, M.: Surf. Coat. Technol. 349, 32 (2018)

19. Rösemann, N., Fiedler, T., Sinning, H.R., Bäker, M.: Results in Materials (2019). https://doi. org/10.1016/j.rinma.2019.100022 
20. Fiedler, T., Groß, R., Rösler, J., Bäker, M.: Surf. Coat. Technol. 316, 219 (2017)

21. Smigelskas, A.D., Kirkendall, E.O.: American institute of mining and metallurgical engineers technical publication. Trans. Metall 171, (1947)

22. Seitz, F.: Acta Metallurgica 1, 355 (1953)

23. Seith, W.: Diffusion in Metallen. Springer (1955)

24. Gottstein, J.: Physikalische Grundlagen der Materialkunde. Springer (2007)

25. Deshpande, S., Sampath, S., Zhang, H.: Surf. Coat. Technol. 200, 5395 (2006)

26. Bose, S.: High Temperature Coatings. Elsevier (2007)

27. Donachie, M.J., Donachie, S.J.: Superalloys. ASM International (2002)

28. Fiedler, T., Rösler, J., Bäker, M.: J. Therm. Spray Technol. 24(8), 1480 (2015)

29. Gülhan, A., Esser, B.: Arc-Heated Facilities as a Tool to Study Aerothermodynamic Problems of Reentry Vehicles. Progress in Astronautics and Aeronautics, vol. 198, chap. 13, pp. 375-403. American Institute of Aeronautics and Astronautics, Reston (2002). https://doi.org/10.2514/5. 9781600866678.0375 .0403

30. Daub, D., Esser, B., Gülhan, A.: AIAA J. (2020) (in press)

31. Daub, D., Willems, S., Esser, B., Gülhan, A.: In: Adams,N., Schröder, W., Radespiel, R., Haidn, O., Sattelmayer, T., Stemmer, C., Weigand, B. (eds.) Future Space-Transport-System Components under High Thermal and Mechanical Loads. Springer (2020)

32. Eiringhaus, D., Riedmann, H., Knab, O.: Internal Report SFB TRR40 (2017)

33. Eiringhaus, D., Riedmann, H., Knab, O.: In: Adams, N., Schröder, W., Radespiel, R., Haidn, O., Sattelmayer, T., Stemmer, C., Weigand, B. (eds) Future Space-Transport-System Components under High Thermal and Mechanical Loads. Springer (2020)

34. Pawlowski, L.: Science and Engineering of Thermal Spray Coatings. Wiley, (2008)

35. Alexander, D., Zinkle, S.J., Rowcliffe, A.F.: J. Nucl. Mater. 271\&272, (1999)

36. Yang, L., Zhou, Y.C., Lu, C.: Acta Materialia 59(17), 6519 (2011)

37. Bäker, M., Fiedler, T., Rösler, J.: Mech. Adv. Mater. Modern Process. 1:5, 1 (2015)

Open Access This chapter is licensed under the terms of the Creative Commons Attribution 4.0 International License (http://creativecommons.org/licenses/by/4.0/), which permits use, sharing, adaptation, distribution and reproduction in any medium or format, as long as you give appropriate credit to the original author(s) and the source, provide a link to the Creative Commons license and indicate if changes were made.

The images or other third party material in this chapter are included in the chapter's Creative Commons license, unless indicated otherwise in a credit line to the material. If material is not included in the chapter's Creative Commons license and your intended use is not permitted by statutory regulation or exceeds the permitted use, you will need to obtain permission directly from the copyright holder.

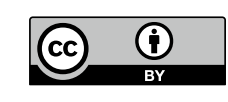

